\title{
To Vaccinate or Not to Vaccinate-Opinion
}

I agree with Dr. Faro's concern about hepatitis B virus infection and his emphasis upon the hepatitis B vaccine. I would like to emphasize universal coverage, beyond the focus upon sexually active adolescents. This population should be cared for because of their high-risk sexual activity. However, they should not be our sole concern. Approximately half of our married population in their 20 s and 30 s get divorced. I've been impressed that divorce for many women is followed by a period of sexual activity with more than one sexual partner. Obstetrician-gynecologists should be proponents for universal hepatitis B immunization for all women. As advocates for the best health care for women, we should not be satisfied with anything less.

Sincerely,

William J. Ledger, M.D. 


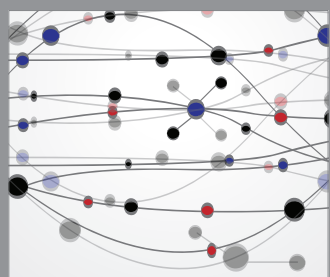

The Scientific World Journal
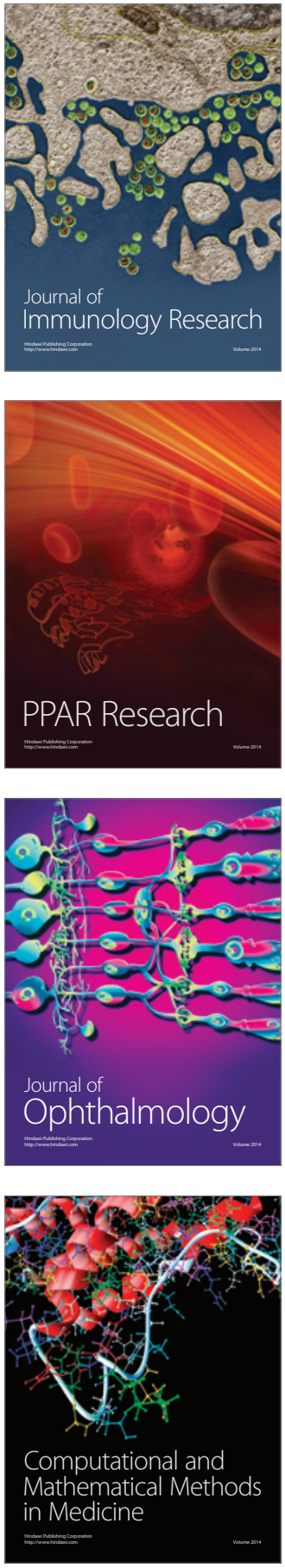

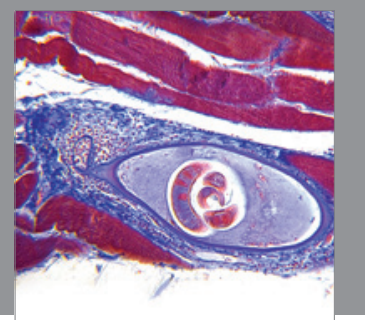

Gastroenterology

Research and Practice
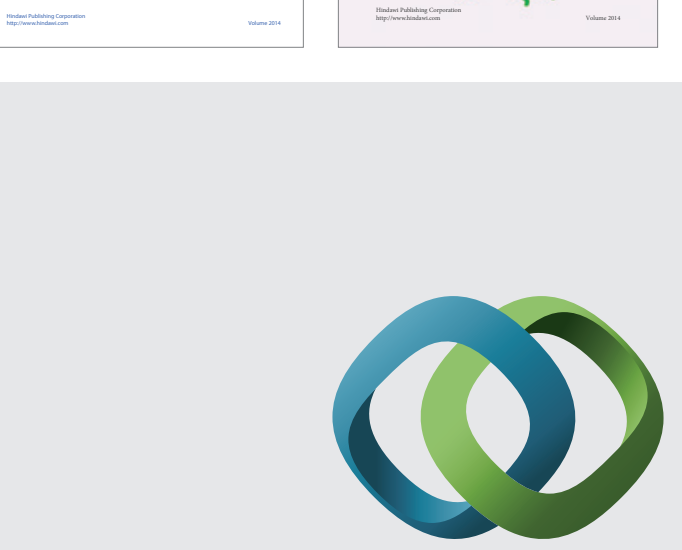

\section{Hindawi}

Submit your manuscripts at

http://www.hindawi.com
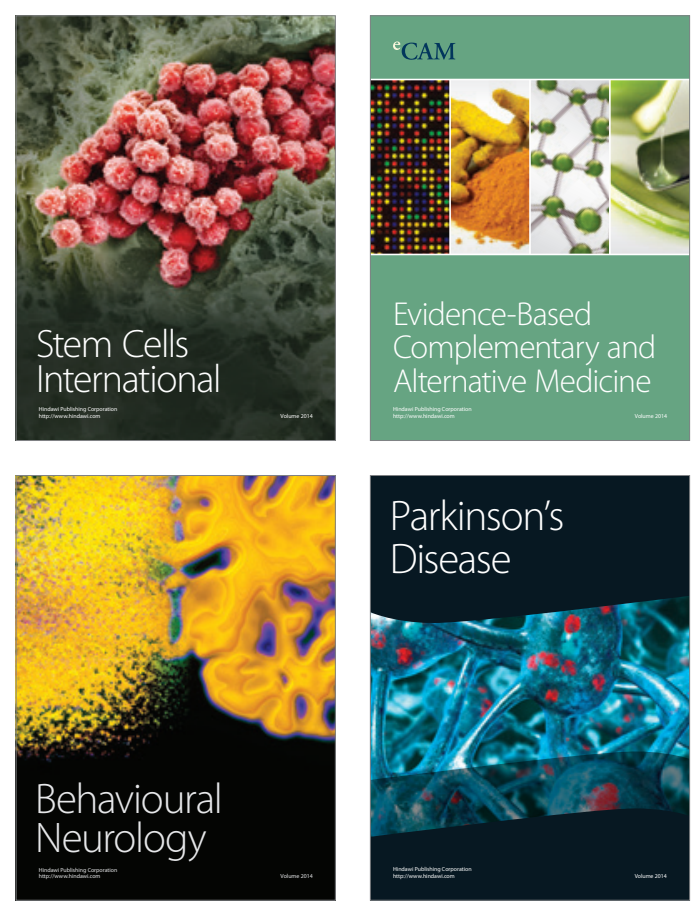

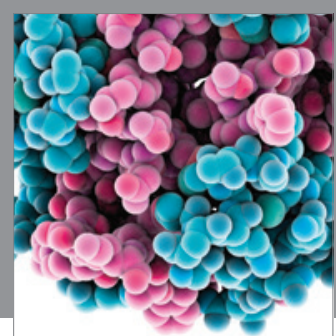

Journal of
Diabetes Research

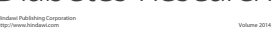

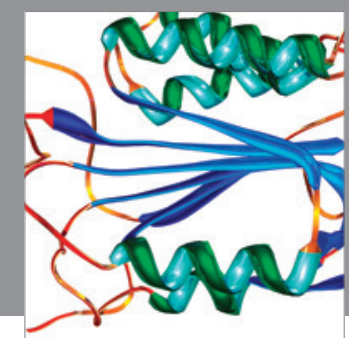

Disease Markers
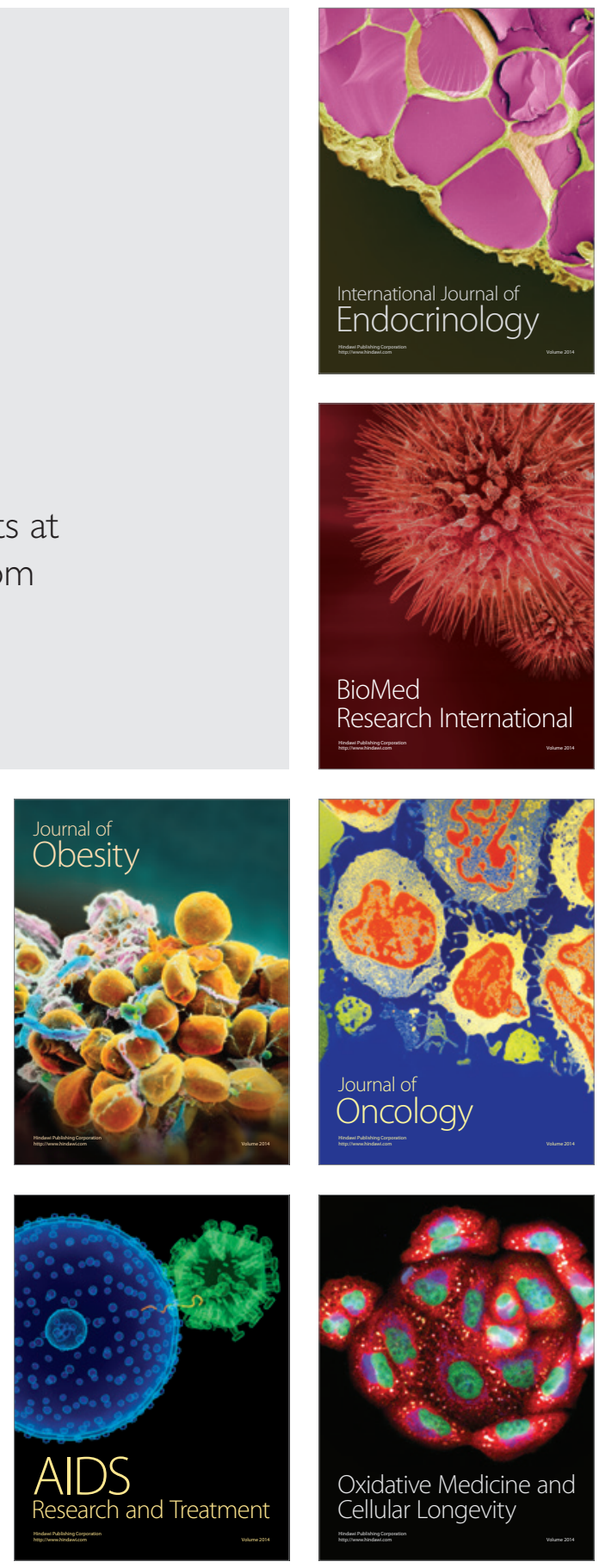